\title{
Vertentes da análise sistêmico-funcional no texto: a construção discursiva em foco
}

\author{
Jônatas Nascimento de BRITO @ \\ Departamento de Ciências Humanas - Universidade do Estado da \\ Bahia (UNEB/Campus Irecê)
}

RESUMO

A conferência proferida pelo professor Carlos Gouveia tratou das articulações teóricas entre pressupostos da Linguística Sistêmico-Funcional (LSF) e as bases da Teoria dos Códigos de Legitimação. Em sua abordagem inicial, o conferencista apresenta os principais aspectos dos modelos teóricos adotados. Por isso, são discutidos os conceitos de função, contexto social, registro e gênero, subjacentes à LSF, bem como as noções de discurso horizontal, discurso vertical, gravidade semântica, densidade semântica, estruturas de conhecimento e estruturas de conhecedores, no âmbito dos códigos de legitimação. Como procedimento de análise, to-

EDITADO POR Raquel Freitag

REVISADO POR Cleide Pedrosa mou-se um texto jornalístico, em que se observou a estruturação textual a partir dos quadros teóricos destacados. Os resultados da análise observam que as amostras textuais se constroem a partir do entrecruzamento entre relações epistêmicas de conhecimento e relações sociais (instâncias e hierarquias) que definem quais sujeitos estão aptos a legitimar o seu discurso.

\section{ABSTRACT}

The conference given by Professor Carlos Gouveia dealt with the theoretical articulations between assumptions of Systemic-Functional Linguistics (SFL) and the bases of the Theory of Legitimation Codes. In his initial approach, the speaker presents the main aspects of the theoretical models adopted. Therefore, the concepts of function, social context, record and gender underlying the SFL are discussed, as well as the notions of horizontal discourse, vertical discourse, semantic gravity, semantic density, knowledge 


\section{REVISTA DA ABRALIN}

structures and knowledge structures, within the scope of codes of legitimation. As a procedure of analysis, a journalistic text was taken, in which the textual structure was observed from the theoretical frameworks highlighted. The results of the analysis observe that the textual samples are constructed from the intersection between epistemic relations of knowledge and social relations (instances and hierarchies) that define which subjects are able to legitimize their discourse.

\section{PALAVRAS-CHAVE}

Texto. Discurso. Legitimação.

\section{KEYWORDS}

Text. Discourse. Legitimation.

Práticas de legitimação e credibilidade de conhecimento em tempos pandémicos: uma análise sistémico-funcional, título da conferência proferida pelo Prof. Dr. Carlos Alberto Marques Gouveia, da Faculdade de Letras da Universidade de Lisboa, no dia 27 de maio de 2020, sob a mediação da Profa. Dra. Cleide Emília Faye Pedrosa, da Universidade Federal de Sergipe. A atividade fez parte da programação do evento Abralin Ao Vivo, iniciativa da Associação Brasileira de Linguística (em parceria com outras instituições nacionais e internacionais) cujo objetivo é promover a reunião de pesquisadores, pesquisadoras, professores e professoras (que atuam e fazem ciência a partir da linguística) para uma discussão sobre as mais diversas vertentes da linguagem num contexto social marcado pelo distanciamento e pelo isolamento domiciliar imposto a partir de medidas de prevenção e combate à pandemia do coronavírus.

Absolutamente atento às atuais demandas impostas pela pandemia, o professor Carlos Gouveia traz para o debate uma rica reflexão que põe em relevo alguns conceitos determinantes para o entendimento da comunicação e transmissão de significados por meio de análises textuais que destacam a atuação dos sujeitos da linguagem na instituição do seu querer-dizer em função do tema sobre o qual discute. A análise empreendida pelo professor ancora-se em dois instrumentos teóricos, a saber: a Linguística Sistêmico-Funcional e a Teoria dos Códigos de Legitimação.

Os pressupostos teóricos da Linguística Sistêmico-Funcional, delineada pelo linguista britânico Michael A. K. Halliday, estão pautados numa perspectiva social da linguagem. Como destacou o professor Gouveia, a LSF é uma teoria social da linguagem centrada na função que a linguagem mobiliza em razão dos usos empreendidos pelos falantes. Nessa perspectiva, nas bases da LSF, encontram-se implicados o contexto social e a mobilização de aspectos semânticos, linguísticos e sintáticos da língua que se articulam mutuamente na construção dos significados. 


\section{REVISTA DA ABRALIN}

Gouveia também destaca, em sua exposição, as categorias de gênero e registro, na perspectiva da LSF. Em texto introdutório sobre a gramática sistêmico-funcional, o autor afirma que as noções de registro e gênero, no domínio da LSF, funcionam como reguladores que asseguram pensar a língua como entidade em uso. Assim, o registro, ligado ao contexto situacional, "pode ser definido como variação de acordo com o uso, ou seja, é uma noção que dá conta do facto de usarmos tipicamente certas e reconhecíveis configurações de recursos linguísticos, em certos contextos" (GOUVEIA, 2009, p. 27).

Como elemento do contexto de cultura, o gênero é a instrumentalização das ações realizadas pelo uso da linguagem. Para cada propósito culturalmente definido, existe um gênero que cumpre a função de realizar a comunicação entre interlocutores. Nesse sentido, Gouveia (2009, p. 28) afirma que "existem tanto géneros quantos os tipos de actividades sociais que reconhecemos na nossa cultura: biografias, tragédias, sonetos (géneros literários), manuais, artigos de jornais, receitas de culinárias, palestras, relatórios, ensaios, seminários, testes, etc."

Já a Teoria dos Códigos de Legitimação tem a ver com o modo como os discursos e os sujeitos dos discursos se mobilizam, tendo em vista os exercícios de orientação que norteiam a estabilização do discurso nas práticas sociais. Entre as principais categorias, Gouveia distingue o discurso horizontal (como práticas de literacia do cotidiano) e o discurso vertical (como práticas acadêmicas e/ou institucionalizadas). Dentro do discurso vertical, Gouveia salienta as categorias de estruturas de conhecimentos hierárquicas, em que ocorre a sistematização que organiza o conhecimento a partir de princípios hierárquicos generalizantes. E as estruturas de conhecimentos horizontais possuem uma natureza mais livre, uma vez que suas segmentações seguem critérios próprios de distinção.

No âmbito da construção do significado dos discursos, Gouveia destaca ainda as noções de gravidade semântica, em que se tem que a relação do texto com o contexto é decisivo para a mobilização do significado pretendido. Por outro lado, a densidade semântica articula símbolos, termos, contextos, conceitos, expressões e gestos que podem, a depender do seu grau de gradação, condensar os significados nos símbolos.

Em sua análise, o professor Carlos Gouveia apresenta um texto jornalístico publicado em um jornal diário de circulação na internet (Observador, jornal on-line de Portugal). Nos procedimentos iniciais da sua análise, o conferencista chama a atenção para a posição política do autor do texto, uma vez que esse aspecto é de extrema relevância para se observar as escolhas linguísticas acionadas para a montagem das cadeias textuais e para veiculação dos seus sentidos.

Entre as principais abordagens salientadas pelo professor em sua análise, cabe fazer menção aos sentidos veiculados pelo texto analisado à luz dos modelos teóricos que orientam a exposição do professor. Inicialmente, destaca-se a instituição hierárquica imposta pelo autor do texto, cujas escolhas linguísticas são feitas a partir da intenção de marcar discursivamente a sua posição social como uma autoridade, a quem é reservado o direito de opinar sobre um assunto (porque tem a especialização técnica necessária). Tal procedimento, como destacou Gouveia, mobiliza estruturas de conhecimento (códigos para legitimar o que pode ser conhecido) por meio da operação de estruturas de conhecedores (instituídas através das relações sociais que cristalizam o direito à voz a determinados grupos e sujeitos). 


\section{REVISTA DA ABRALIN}

É dentro desse quadro que se mobilizam os códigos de conhecimento e de elite, tratados pelo professor Gouveia em sua abordagem teórica. No âmbito da análise sistêmico-funcional, ganha destaque a ideia de língua como escolha, tal como anotou Halliday (1974). Segundo o teórico da LSF, existe no plano de funcionamento da linguagem uma base organizadora que modela as escolhas significativas dentro do uso da língua. Essa base está fincada no processo de descrição da forma linguística em que são desenvolvidos os planos gramatical e lexical. É essa rede de sistemas que é responsável por viabilizar o cumprimento das demandas sociais que se instanciam no plano da organização linguística. Nesse sentido, a elaboração de textos vai sempre supor a existência de propósitos comunicativos que são alcançados pelas funções desempenhadas pela linguagem na atividade de uso.

Essa indicação põe em relevo o aspecto de que a língua se constitui enquanto é usada para estabelecer a interação, o que põe em evidência a caracterização da pragmática observada no concreto uso da linguagem. Tomando-se, por exemplo, os elementos destacados por Gouveia, em sua análise, é possível observar que o texto é construído pela mobilização de itens lexicais que favorecem a legitimação do seu autor como uma autoridade, um conhecedor cujo direito à fala e à disseminação de significados deve ser garantido e assegurado.

Portanto, é possível dizer que a discussão proposta pelo professor Carlos Gouveia em muito contribui para o entendimento dos processos subjacentes à atividade de elaboração de textos e de circulação de sentidos na sociedade. Em plena pandemia de Covid-19, a análise linguístico-textual-discursiva que o professor apresenta traz às claras o jogo de disputa que se estabelece nos diversos contextos sociais (jornalístico, científico, político etc.), cuja finalidade é a viabilização de uma narrativa ou um ponto de vista como oficial e legítimo em detrimento de outros (não oficiais e ilegítimos). Daí a necessidade de se assumir um papel crítico diante desse jogo retórico que se descortina diante dos olhos de todos: cada vez mais se faz necessário o exercício conciso de apuração das informações e de ponderação dos fatos. Sem dúvida, a proposta do professor Carlos Gouveia deixa esse ensinamento.

\section{REFERÊNCIAS}

GOUVEIA, C. A. M. Texto e gramática: uma introdução à linguística sistémico-funcional. Matraga, v. 16, n. 24, p. 13-47, jan./jun. de 2009.

HALLIDAY, M. A. K. et al. As ciências linguísticas e o ensino de línguas. Tradução de Myriam Freire Moreau. Petrópolis: Vozes, 1974.

PRÁTICAS de legitimação e credibilidade de conhecimento em tempos pandémicos: uma análise sistémico-funcional. Conferência apresentada por Carlos A. M. Gouveia [s.l., s.n], 2020.1 vídeo (1h 39min09s). Publicado pelo canal da Associação Brasileira de Linguística. Disponível em: https://www.youtube.com/watch?v=RQoRDArRiXA. Acesso em: 27 mai 2020. 